for analysis of chemical and antigenic structure, and for in vitro evaluation of trypanocidal agents.

The development of this medium proved a promising starting point for a complete analysis of the nutritional requirements of $T$. cruzi. Experimental evidenee, which will be published elsewhere, indicates that the tomato juice may be replaced by known growth factors and that the function of the serum albumin in our medium depends on its highly specific capacity to bind certain essential lipids (for example, unsaturated fatty acids) ${ }^{8}$ which are trypanolytic per se.

Thus the well-established dependence of these hæmoflagellates on certain blood fractions may be explained by the surface action of such blood lipids which facilitate the absorption of known growth factors.

We are indebted to Prof. S. Adler for the strains employed in this work and for his constant interest.

NATHAN Citri

Nathan Grossowicz

Department of Bacteriology,

Hebrew University-Hadassah Medical School, Jerusalem.

Jan. 27.

${ }^{1}$ Chang, S. L., J. Inf. Dis., 80, 164 (1947).

2 Seneca, H., and Henderson, E., Amer. J.Hyg., 53, 17 (1951).

${ }^{8}$ Grossowicz, N., and Kligler, J. J., Amer. J. Pub. Health, 32, 745 (1942).

-Grossowicz, N., Proc. Soc. Exp. Biol. and Med., 49, 8 (1942).

- Lwoff, M., C.R. Suc. Biol., 107, 1234 (1931).

- McRary, W. L., Noble, E. R., and Tondevold, E. L., Science, 115 , 288 (1952).

'Little, P. A., and SubbaRow, Y., J. Bact., 50, 57 (1945).

B Luck, J. M., in Disc. Farad. Soc., 6, 44 (1949)

- Adler, S., and Ashbel, R., Arch. Zool. Ital., 20, 66 (1934).

\section{A Toxic Nitro Compound from Streptomyces thioluteus}

A LARGE amount of a yellow crystalline compound which is very toxic to animals has been obtained from cultures of Streptomyces thioluteus ${ }^{1}$. This compound (I) has been found to contain a nitro group.

The molecular formula of the compound (m.p. 158 corresponded to $\mathrm{C}_{21} \mathrm{H}_{21} \mathrm{O}_{6} \mathrm{~N}$. Spectroscopic data obtained in ethanol were as follows : $\lambda_{\max } .256 \mathrm{~m} \mu$ $(\log \varepsilon, 4 \cdot 37) ; 345 \mathrm{~m} \mu(\log \varepsilon, 4 \cdot 26)$. The nitro group test ${ }^{2}$ with ferrous ammonium sulphate was positive. Clemmensen reduction of I gave white crystals, m.p. $210-5^{\ominus}(\mathrm{II})$, with a positive test for an aromatic amino group.

Acid hydrolysis with alcoholic $1 N$ hydrochloric acid converted I into yellow needles of melting point $194-5^{\circ}$ (III), which showed a positive test for the nitro group. A yellow acetate (m.p. 182-4 ${ }^{\circ}$, IV) and a white reductive acetate (m.p. $216-8^{\circ}$ (dec.), V) of these yellow needles were also prepared. Reductive acetylation of IV gave V, and acetylation of II also gave V. The number of acetyl groups in IV and V were 1 and 2, respectively.

Oxidation of compound III with alkaline permangenate yielded white crystals, melting point $234-5^{\circ}$ (in sealed tube), with the composition $\mathrm{C}_{7} \mathrm{H}_{5} \mathrm{O}_{4} \mathrm{~N}$ (VI). This compound showed $\lambda_{\max .} 260 \mathrm{~m} \mu(\log \varepsilon, 4 \cdot 03)$ in ethanol and gave positive tests for the nitro group and carboxyl group. Methylation with diazomethane converted compound VI into white plates, melting point 92-3 ${ }^{\circ}$, which gave no melting point depression upon admixture with methyl $p$-nitrobenzoate.
In the infra-red spectrum two bands corresponding to a nitro group attached to an aromatic nucleus, that is, around 6.3 and $7.5 \mu$, were present in compounds I, III and IV, and ArNHCO - bands at 5.94 and $6.52 \mu$ were present in $V$.

Hence, I has the partial structure<smiles>CC(C)(C)c1ccc([N+](=O)[O-])cc1</smiles>

We are grateful to Dr. K. Iwadare, of the Banyu Pharmaceutical Co., who has generously provided us with material.

\section{Yoshimasa Hirata}

Department of Chemistry, Nagoya University, Chikusa-ku, Nagoya,

Japan. $\quad$ TAKayuki NarTô Kunto OKUHARA

Banyu Pharmaceutical Co., Okazaki, Japan.

1 Maeda, K., J. Antibiotics, 6, 137 (1953)

${ }^{2}$ Hearon, W. M., and Gustauson, G., Indust. Eng. Chem., Anal. Ed., 9, 352 (1937).

\section{Occurrence of Susceptibility to Carbon Dioxide in Drosophila melanogaster from Different Countries}

UNTIL recently, all virus-induced susceptibility to carbon dioxide of Drosophila melanogaster ${ }^{1}$ seemed derived from one stock, and repeated search for another occurrence in many laboratory stocks remained unavailing. Some years ago, one of us (F. T.) discovered that $D$. melanogaster flies, recently trapped in the neighbourhood of Rothamsted Experimental Station, Harpenden, Herts, showed the characteristic hereditary carbon dioxide susceptibility, but as the other of us (H.K.) had kept at Rothamsted a few years earlier a substrain of L'Héritier's original stock, it was impossible to be sure that an escape was not responsible. However, a recent report has made it clear that carbon dioxide-susceptible flies, far from being rare, occurred in about one-third of all freshly trapped strains of $D$. melanogaster in France ${ }^{2}$. In addition, we are indebted to a personal communication from Prof. L'Héritier in which he states that he found susceptible flies in cultures from Israel but could not detect the susceptibility in flies from Africa or Japan.

In our own investigation, single flies trapped by ourselves, their offspring or flies supplied by other institutions were bred in vials at $24^{\circ} \mathrm{C}$. and tested about one week after emergence. D. melanogaster is often transported with fruit, and the place of trapping need not necessarily be the place of origin. The results are summarized in Table 1.

It can be seen from the above results that carbon dioxide susceptibility occurs widely, but that flies from the same locality may sometimes be carbon dioxide-susceptible and sometimes carbon dioxideresistant. The virus responsible for the susceptibility seems to be lost more or less quickly under laboratory conditions, which probably accounts for the fact that the susceptibility has not been rediscovered before.

The great differences among the resistant females from different strains in the rates of infection by susceptible males are probably due to some genetical and cytoplasmic ${ }^{3}$ properties of these strains, but it is at present difficult to correlate these with any environmental factor. 